\title{
Design and Validation of the PercOV-S Questionnaire for Measuring Perceived Obstetric Violence in Nursing, Midwifery and Medical Students
}

\author{
Desirée Mena-Tudela ${ }^{1, * \mathbb{C}}$, Agueda Cervera-Gasch ${ }^{1}{ }^{\mathbb{D}}$, María José Alemany-Anchel ${ }^{2}$, \\ Laura Andreu-Pejó $^{1}{ }^{(1)}$ and Víctor Manuel González-Chordá ${ }^{1}$ \\ 1 Department of Nursing, Faculty of Health Sciences, Universitat Jaume I, Avda. Sos I Baynat s/n, \\ 12071 Castellón, Spain; cerveraa@uji.es (A.C.-G.); pejo@uji.es (L.A.-P.); vchorda@uji.es (V.M.G.-C.) \\ 2 Midwives' Teaching Unit of the Comunitat Valenciana, 46017 Valencia, Spain; alemany_marjos@gva.es \\ * Correspondence: dmena@uji.es
}

Received: 4 September 2020; Accepted: 27 October 2020; Published: 30 October 2020

\begin{abstract}
Background: Obstetric violence could be defined as the dehumanized treatment or abuse of health professionals towards the body or reproductive process of women. Some practices associated with obstetric violence have been routinely standardized and do not include the woman in decision making. This type of violence has consequences for the health of both the mother and the baby and that of the professionals who practice or observed it. Methods: A questionnaire consisting of 33 items that measured perception through a Likert scale was developed. Some sociodemographic variables were collected. The instrument was applied to a sample of nursing, medicine and midwifery students to determine its psychometric properties. Results: The final sample consisted of 153 students. The Kaiser-Meyer-Olkin $(p=0.918)$ and Barlett tests $(p \leq 0.001)$ allowed for factor analysis, which explained $54.47 \%$ of the variance in two factors called protocolized-visible obstetric violence and non-protocolized-invisible obstetric violence. Conclusions: The PercOV-S (Perception of Obstetric Violence in Students) instrument was validated. The distribution and content of the two factors are closely related to obstetric violence against women. The existence of statistically significant relationships between the sociodemographic variables collected and the global measurements, domains and items of the PercOV-S scale highlight the normalization of obstetric violence as a central factor for future studies.
\end{abstract}

Keywords: obstetric violence; gender violence; childbirth; birth; health sciences students

\section{Introduction}

Some definitions of Obstetric Violence (OV) exist, although the United Nations Population Fund (UNFPA) has recognized that there is a lack of consensus on how to define and measure violence against women during delivery care in health centres [1]. However, some South American countries have legislated around OV and provided a definition. For example, Venezuela defines this term as "the appropriation of the body and reproductive processes of women by health personnel, which is expressed as dehumanized treatment, an abuse of medication and the conversion of natural processes into pathological ones, bringing with it loss of autonomy and the ability to decide freely about their bodies and sexuality, negatively impacting the quality of life of women" [2].

The World Health Organization (WHO) describes some practices that make OV visible: disrespectful and offensive treatment during childbirth, physical abuse, profound humiliation and verbal abuse, the performance of medical procedures without consent or with coercion (including sterilization), lack of confidentiality, failure to obtain full informed consent, refusal to 
administer analgesics, flagrant violations of privacy, rejection of admission to a health centre, neglect of women during childbirth, and retaining women and newborns at a health centre due to their inability to pay [3], among issues. In 2015, the International Federation of Gynaecology and Obstetrics (FIGO) proposed the Mother and Baby Friendly Birth Facility (MBFBF), which identified 7 categories of disrespect and abuse in childbirth [4]. In these categories, examples of obvious abuse, such as hitting the woman; forcing her legs apart; placing pressure on the fundus; not providing privacy (spatial, visual or auditory); humiliation; screaming at or demeaning the woman; and discrimination based on ethnic origin, age, marital status, language, economic status or educational level, among other violations, were exposed [4].

Studies identify that approximately $30 \%$ of childbirth experiences can be considered traumatic and/or as having OV components [5,6]. Moreover, OV can be found around the world in all continents: America [7-9], Africa [10-12], Asia [13], Europe [6,14,15] and Australia [16,17]. These negative experiences and the presence or practice of OV have consequences for the woman and her newborn, for society and for the health professionals who observe or practice it. Among the main consequences for women, the impact on physical, sexual and psychological health can be highlighted $[5,18]$; specific examples are the loss of the uterus after an unnecessary c-section or permanent pain during intercourse with penetration after an episiotomy [19]. For health personnel, the most prominent consequence is secondary traumatic stress and compassionate fatigue [20] that may even lead professionals to abandon professional practice [21].

Many of the health interventions related to OV are normalized; therefore, health personnel may not even be aware that they are engaging in violent practices against a woman [22]. Scientific literature reveals that the factors that perpetuate OV include a lack of proper training for health professionals [1,23]. With respect to health science students, although the literature highlights the importance of providing high-quality woman-centred care, many forms of lack of respect and abuse during childbirth continue to be reported [24]. With all this, the negative obstetric practices and the existing literature make us think about an important public health problem: obstetric violence. Incorporating techniques to prevent obstetric violence seems necessary. Making health science students aware of this problem can be part of the solution to this problem. Among this literature, no validated instruments have been identified to measure the perception of OV by health science students. Thus, with this study, we intend to construct and validate an instrument (the PercOV-S, Perception of Obstetric Violence in Students) that can evaluate the health sciences students' perceptions regarding certain practices related to obstetric violence.

\section{Materials and Methods}

\subsection{Design}

An instrumental design was used in this study [25] to develop and validate an instrument that would allow the study of health sciences students' perceptions of obstetric violence (PercOV-S). The study was conducted between November 2018 and October 2019. The study was approved by the Management of the Nursing Research Group (241) of the Universitat Jaume I, and the Deontological Committee of the Universitat de Jaume I (CD/26/2020) approved this study. The project was designed in accordance with the Organic Law 03/2018 of December 5, Protection of Personal Data and Guarantee of Digital Rights. In addition, the principles of the Declaration of Helsinki were respected.

\subsection{Setting and Participants}

The study was conducted with nursing, midwifery and medical students. Nursing and medical students belong to the Universitat Jaume I (Spain). Midwifery students are from the Valencian School of Health Studies (EVES). The established sample size was 5 subjects per item, according to the recommendations of the literature [26]. All students enrolled in the nursing or medical program during academic year 2018/2019 at the Universitat Jaume I (Spain) and who attended an educational seminar 
on OV were eligible. All midwifery students present in the classroom on the day of data collection were included. Finally, the questionnaire was administered to a sample of 169 nursing, medical and midwifery students to determine the psychometric properties of the instrument.

\subsection{Instruments Validation and Collection}

The development and validation of the PercOV-S instrument were carried out according to the recommendations of the literature [27]. First, a literature review was conducted to confirm that no other instruments had been developed specifically for the same aim in the last 5 years. The PubMed, Cochrane databases, and Cumulative Index to Nursing and Allied Health Literature were consulted, 5-year-old articles in Spanish and English were included. The Spanish Clinical Practice of Normal Birth Care Guide was consulted [28,29]. This review was used to determine which interventions could be related to obstetric violence. The first version, obtained by a group of 3 members of the research group, comprised 33 items measured with the Likert scale (between November and December 2018).

In the next step, content validity was studied. For content validation, a heterogeneous group of experts in health and gender composed of a graduate in medicine, a nurse, a lawyer and a mother with previous experience with OV was formed. The experts received the scale $72 \mathrm{~h}$ before the meeting by e-mail. A single online meeting was necessary to reach agreement, and no items were changed (between December 2018 and January 2019).

Finally, the questionnaire was administered to nursing and medical students in March 2019. Midwifery students received the questionnaire from March to June 2019. To collect the data, the paper-based questionnaire was administered to nursing and medical students before an educational seminar on obstetric violence. For midwifery students, the questionnaire was sent online before the training.

\subsection{Measurement}

The final questionnaire consisted of 33 items that measured the students' perceptions regarding OV using a 5-level ascending Likert scale (1: no OV; 5: a considerable amount of OV). All items were positively written. Five points can be obtained for the maximum perception of obstetric violence for each item. Higher scores indicate an increased perception of obstetric violence. In addition, the following sociodemographic variables were collected and analysed: age, gender (male/female), area of study (nursing, medicine and midwifery), health experience in gynaecology and obstetrics services (yes/no), witnessing a birth (yes/no), and personal experience with pregnancies and births (yes/no).

\subsection{Data Analysis}

First, the internal consistency of the questionnaire and its domains were determined with Cronbach's alpha. To study construct validity, the viability of the exploratory factor analysis was confirmed with the Kaiser-Meyer-Olkin test $(\mathrm{KMO}=0.918)$ and Bartlett's test of sphericity $(p \leq 0.001)$. Factor extraction was performed using principal components with varimax rotation. Second, a descriptive analysis of the sample was performed according to the nature of the variables (mean, standard deviation, maximum and minimum, and 95\% confidence intervals were determined for quantitative variables, and frequency and percentage were determined for qualitative variables). Finally, the questionnaire results were analysed descriptively, and statistically significant relationships between sociodemographic variables and perceptions of OV were determined with the Mann-Whitney U test and the Kruskal-Wallis test. Calculations were performed using SPSS for Windows, and the level of statistical significance was established at $p \leq 0.05$. 


\section{Results}

\subsection{Sociodemographic Characteristics}

A total of 169 questionnaires were collected, of which $9.46 \%(n=16)$ were eliminated due to poor completion. The sample consisted of 153 questionnaires. The distribution of the sample according to area of study was as follows: nursing students, $60.8 \%(\mathrm{n}=93)$; medical students, $9.2 \%(\mathrm{n}=14)$; and midwifery students, $30.1 \%(n=46)$. The mean age of the sample was 23.34 years $( \pm 5.426 ;$ minimum $=19$, maximum $=61)$. A total of $89.5 \%(n=137)$ of the sample was female. Forty percent $(n=62)$ of the sample had worked or completed internships at gynaecology and obstetrics services; of these, 38.7\% $(n=24)$ had done so less than a year ago, 51.6\% $(n=32)$ had done so between 1 and 4 years ago, and $9.7 \%(n=6)$ had done so more than 4 years ago. A total of $39.2 \%(n=60)$ of the students had witnessed a childbirth; of these, $90.3 \%(n=56)$ had done so between less than 1 year and 4 years ago. A total of $5.9 \%(n=9)$ were pregnant, and $3.9 \%(n=6)$ had given birth (Table 1$)$.

Table 1. Sociodemographic characteristics $(\mathrm{N}=153)$.

\begin{tabular}{|c|c|c|c|c|c|c|c|c|}
\hline & \multicolumn{2}{|c|}{$\begin{array}{l}\text { Nursing Students } \\
\quad(n=93)\end{array}$} & \multicolumn{2}{|c|}{$\begin{array}{l}\text { Medical Students } \\
\quad(\mathrm{n}=14)\end{array}$} & \multicolumn{2}{|c|}{$\begin{array}{l}\text { Midwifery Students } \\
\quad(\mathrm{n}=46)\end{array}$} & \multicolumn{2}{|c|}{$\begin{array}{l}\text { Overall Score } \\
(\mathbf{N}=153)\end{array}$} \\
\hline & $\mathbf{n}$ & $\%$ & $\mathbf{n}$ & $\%$ & $\mathbf{n}$ & $\%$ & $\mathbf{n}$ & $\%$ \\
\hline \multicolumn{9}{|l|}{ Gender } \\
\hline Male & 10 & 10.8 & 1 & 7.1 & 5 & 10.9 & 16 & 10.5 \\
\hline Female & 86 & 89.2 & 13 & 92.9 & 41 & 89.1 & 137 & 89.5 \\
\hline \multicolumn{9}{|c|}{ Obstetrics-gynaecology practical experience } \\
\hline Yes & 25 & 26.9 & 5 & 35.7 & 32 & 69.6 & 62 & 40.5 \\
\hline No & 68 & 73.1 & 9 & 64.3 & 14 & 30.4 & 91 & 59.5 \\
\hline \multicolumn{9}{|c|}{ Witnessed a birth } \\
\hline Yes & 20 & 21.5 & 2 & 14.3 & 38 & 82.6 & 60 & 39.2 \\
\hline No & 73 & 78.5 & 12 & 85.7 & 8 & 17.4 & 93 & 60.8 \\
\hline \multicolumn{9}{|c|}{ Personal experience with pregnancy } \\
\hline Yes & 5 & 5.4 & - & - & 4 & 8.7 & 9 & 5.9 \\
\hline No & 88 & 94.6 & 14 & 100 & 42 & 91.3 & 144 & 94.1 \\
\hline \multicolumn{9}{|c|}{ Personal experience with birth } \\
\hline Yes & 3 & 3.2 & - & - & 3 & 6.5 & 6 & 3.9 \\
\hline No & 90 & 96.8 & 14 & 100 & 43 & 93.5 & 147 & 96.1 \\
\hline
\end{tabular}

\subsection{Psychometric Properties}

There were no comprehension problems with the items. The viability of the factor analysis was confirmed by the KMO test $(p=0.918)$ and Bartlett's test for sphericity $\left(X^{2}=3767.745 ; p \leq 0.001\right)$. The factor analysis explained $54.47 \%$ of the variance in the two factors. The first factor or domain explained $43.11 \%$ of the variance and comprised 8 items. The second factor or domain explained $11.36 \%$ of the variance and comprised 25 items. All items showed factor loads greater than 0.4 except "Allowing skin-to-skin contact after the paediatric examination", although the research team decided to keep it to obtain relevant information on a specific procedure. The overall reliability of the questionnaire $(\alpha=0.936)$ and its domains was excellent (domain $1, \alpha=0.802$; domain $2, \alpha=0.952$ ), and it was decided not to eliminate any item by increasing the $\alpha$ value. Table 2 shows the results of the exploratory factor analysis and reliability tests. 
Table 2. Matrix of components and results of the factor analysis of the PercOV-S (Perception of Obstetric Violence in Students) instrument $(\mathrm{N}=153)$.

\begin{tabular}{|c|c|c|c|c|}
\hline \multirow{2}{*}{ Domains and Items } & \multicolumn{3}{|c|}{ Factors } & \multirow{2}{*}{ Communalities } \\
\hline & 1 & 2 & $\alpha$ & \\
\hline Domain 1 & & & 0.802 & \\
\hline 1. Inserting an intravenous channel & -0.084 & 0.507 & 0.939 & 0.558 \\
\hline 2. Directing the woman's position & -0.023 & 0.743 & 0.940 & 0.569 \\
\hline 3. Accelerate the birthing process artificially & 0.391 & 0.608 & 0.935 & 0.680 \\
\hline 4. Administering routine enemas & 0.450 & 0.597 & 0.934 & 0.601 \\
\hline 6. Performing routine genital shaving & 0.526 & 0.593 & 0.933 & 0.662 \\
\hline $\begin{array}{l}\text { 15. Enforcing the lithotomy position (i.e., position in which the } \\
\text { patient is supported on her back with her legs resting on the } \\
\text { stirrups of a surgical table or chair) }\end{array}$ & 0.374 & 0.601 & 0.935 & 0.684 \\
\hline 16. Allowing accompaniment during the second stage & 0.146 & 0.452 & 0.939 & 0.529 \\
\hline 28. Immediately cutting the cord & -0.412 & 0.491 & 0.934 & 0.652 \\
\hline Domain 2 & & & 0.952 & \\
\hline $\begin{array}{l}\text { 5. Performing routine amniorrhexis (i.e., artificial rupture } \\
\text { of membranes) }\end{array}$ & 0.612 & 0.313 & 0.933 & 0.677 \\
\hline 7. Immobilizing the woman & 0.731 & 0.148 & 0.932 & 0.615 \\
\hline 8. Performing a pelvic exam without consent & 0.901 & -0.255 & 0.932 & 0.896 \\
\hline 9. Not offering measures for pain & 0.768 & -0.197 & 0.933 & 0.681 \\
\hline 10. Encouraging the use of an epidural & 0.639 & 0.388 & 0.932 & 0.606 \\
\hline 11. Not preserving privacy & 0.894 & -0.150 & 0.932 & 0.833 \\
\hline $\begin{array}{l}\text { 12. Convincing the woman to undergo a c-section to end labour } \\
\text { quickly and without pain }\end{array}$ & 0.748 & -0.015 & 0.933 & 0.634 \\
\hline 13. Not considering the woman's decision & 0.865 & -0.226 & 0.933 & 0.808 \\
\hline 14. Taking pictures without permission & 0.901 & -0.267 & 0.932 & 0.897 \\
\hline $\begin{array}{l}\text { 17. Performing routine episiotomy (i.e., incision in the perineum } \\
\text { of a woman in labour) }\end{array}$ & 0.620 & -0.078 & 0.934 & 0.567 \\
\hline 18. Saying "You do not know how to push" & 0.808 & -0.234 & 0.933 & 0.757 \\
\hline $\begin{array}{l}\text { 19. Performing the Kristeller manoeuvre (i.e., fundal pressure in } \\
\text { second stage labour) }\end{array}$ & 0.543 & -0.013 & 0.934 & 0.643 \\
\hline 20. Performing an episiotomy without anaesthesia & 0.636 & -0.148 & 0.934 & 0.629 \\
\hline 21. Prohibiting eating and drinking & 0.444 & 0.351 & 0.934 & 0.545 \\
\hline 22. Not providing covering/heating during delivery & 0.767 & -0.105 & 0.933 & 0.608 \\
\hline 23. Saying "Stop complaining; it is not that bad" & 0.854 & -0.320 & 0.933 & 0.839 \\
\hline 24. Not letting the woman shout & 0.740 & -0.015 & 0.932 & 0.563 \\
\hline 25. Performing a caesarean section due to slow dilation & 0.627 & 0.138 & 0.933 & 0.491 \\
\hline 26. Performing an emergency caesarean section without consent & 0.685 & 0.072 & 0.933 & 0.654 \\
\hline $\begin{array}{l}\text { 27. Not allowing accompaniment in cases of instrumentation or } \\
\text { caesarean section }\end{array}$ & 0.715 & -0.102 & 0.933 & 0.622 \\
\hline 29. Suturing a tear without anaesthesia & 0.757 & -0.087 & 0.933 & 0.664 \\
\hline 30. Separating the mother and newborn & 0.866 & -0.280 & 0.933 & 0.860 \\
\hline 31. Allowing skin-to-skin contact after the paediatric examination & 0.293 & 0.110 & 0.937 & 0.589 \\
\hline 32. Taking the baby to the nursery & 0.570 & 0.192 & 0.934 & 0.507 \\
\hline 33. Giving formula without the mother's consent & 0.846 & -0.216 & 0.932 & 0.810 \\
\hline
\end{tabular}

\subsection{Student Perception Scale of Obstetric Violence}

The overall mean score of the questionnaire was 4.14 ( $\mathrm{SD} \pm 0.61 ; 95 \% \mathrm{CI}=4.03-4.23)$, indicating a high perception of obstetric violence. The domain 1 score obtained a mean score of 3.17 ( $\mathrm{SD} \pm 0.86$; $95 \% \mathrm{CI}=3.03-3.32$ ); for domain 2 , the mean score was 4.25 ( $\mathrm{SD} \pm 0.61 ; 95 \% \mathrm{CI}=4.15-4.35$ ).

Regarding inferential analysis, the overall PercOV-S score showed some statistically significant relationships to the sociodemographic variables sex (male: $\mathrm{m}=3.68, \pm 0.95$; female: $\mathrm{m}=4.18, \pm 0.52$, $p=0.029$ ); area of study (nursing: $\mathrm{m}=4.07, \pm 0.56$; medicine: $\mathrm{m}=4.13, \pm 0.48$; and midwifery: $\mathrm{m}=4.25, \pm 0.66, p=0.011$ ) and completion of internships in an obstetrics and gynaecology department (yes: $\mathrm{m}=4.22, \pm 0.58$; no: $\mathrm{m}=4.06, \pm 0.60, p=0.019$ ). Domain 1 showed a statistically significant difference by gender (male: $\mathrm{m}=3.71, \pm 1.08$; female: $\mathrm{m}=4.31, \pm 0.50, p=0.004$ ), while domain 2 showed a significant effect of area of study (nursing: $\mathrm{m}=3.00, \pm 0.88$; medicine: $\mathrm{m}=3.00, \pm 1.05$; 
and midwifery: $\mathrm{m}=3.53, \pm 0.68, p=0.004)$ and completion of an internship in the gynaecology and obstetrics department (yes: $\mathrm{m}=3.43, \pm 0.82$; no: $\mathrm{m}=2.98, \pm 0.85, p=0.003$ ) (Table 3). Table 4 shows the results of the PercOV-S items according to the area of study.

Table 3. Descriptive and comparative results of the sociodemographic variables and PercOV-S.

\begin{tabular}{|c|c|c|c|c|c|c|c|c|c|}
\hline & \multicolumn{3}{|c|}{ Global } & \multicolumn{3}{|c|}{ Domain 1} & \multicolumn{3}{|c|}{ Domain 2} \\
\hline & $M$ & $S D$ & $p^{1}$ & $M$ & $S D$ & $p^{1}$ & $M$ & $S D$ & $p^{1}$ \\
\hline \multicolumn{10}{|l|}{ Sex } \\
\hline Male & 3.68 & 0.95 & 0.029 & 3.08 & 0.98 & 0.661 & 3.71 & 1.08 & 0.004 \\
\hline Female & 4.18 & 0.52 & & 3.18 & 0.85 & & 4.31 & 0.50 & \\
\hline \multicolumn{10}{|c|}{ Area of study } \\
\hline Nursing & 4.07 & 0.56 & & 3.00 & 0.88 & & 4.23 & 0.56 & \\
\hline Medicine & 4.13 & 0.48 & $0.011^{2}$ & 3.00 & 1.05 & $0.004^{2}$ & 4.32 & 0.33 & $0.182^{2}$ \\
\hline Midwifery & 4.25 & 0.66 & & 3.53 & 0.68 & & 4.29 & 0.72 & \\
\hline \multicolumn{10}{|c|}{ Obstetrics-gynaecology practical experience } \\
\hline Yes & 4.22 & 0.58 & O 019 & 3.43 & 0.82 & $0 \cap 003$ & 4.29 & 0.56 & 0318 \\
\hline No & 4.06 & 0.60 & 0.019 & 2.98 & 0.85 & 0.003 & 4.23 & 0.63 & 0.318 \\
\hline \multicolumn{10}{|c|}{ Witnessed a birth } \\
\hline Yes & 4.17 & 0.67 & مQ9 & 3.32 & 0.83 & 0116 & 4.25 & 0.69 & 0101 \\
\hline No & 4.10 & 0.54 & 0.099 & 3.07 & 0.87 & 0.116 & 4.25 & 0.53 & 0.191 \\
\hline \multicolumn{10}{|c|}{ Personal experience with pregnancy } \\
\hline Yes & 3.66 & 1.20 & ( 477 & 3.01 & 1.26 & & 3.71 & 1.25 & \\
\hline No & 4.16 & 0.52 & $0.4 / 1$ & 3.18 & 0.83 & 0.727 & 4.29 & 0.52 & 0.429 \\
\hline \multicolumn{10}{|c|}{ Personal experience with birth } \\
\hline Yes & 3.33 & 1.30 & 0143 & 2.75 & 1.08 & & 3.38 & 1.43 & 0189 \\
\hline No & 4.16 & 0.53 & 0.143 & 3.19 & 0.85 & 0.301 & 4.29 & 0.52 & 0.109 \\
\hline
\end{tabular}

Table 4. Descriptive and comparative results of the area of study and PercOV-S items.

\begin{tabular}{|c|c|c|c|c|c|c|c|}
\hline & \multicolumn{7}{|c|}{ Area of Study } \\
\hline & \multicolumn{2}{|c|}{ Nursing } & \multicolumn{2}{|c|}{ Medicine } & \multicolumn{2}{|c|}{ Midwifery } & \multirow{2}{*}{$p^{1}$} \\
\hline & $M$ & $S D$ & $M$ & $S D$ & $M$ & $S D$ & \\
\hline Inserting an intravenous channel & 2.12 & 1.16 & 2.38 & 1.32 & 2.11 & 0.99 & 0.747 \\
\hline Directing the woman's position & 2.09 & 1.33 & 2.36 & 1.55 & 2.74 & 1.54 & 0.051 \\
\hline Accelerating the birthing process artificially & 3.34 & 1.30 & 3.36 & 1.39 & 4.02 & 1.06 & 0.010 \\
\hline Administering routine enemas & 3.18 & 1.35 & 2.71 & 1.43 & 4.02 & 1.16 & $\leq 0.001$ \\
\hline Performing routine amniorrhexis & 4.12 & 0.90 & 3.86 & 1.16 & 4.20 & 1.02 & 0.471 \\
\hline Performing routine genital shaving & 3.42 & 1.43 & 2.77 & 1.36 & 4.28 & 1.08 & $\leq 0.001$ \\
\hline Immobilizing the woman & 4.51 & 0.84 & 4.36 & 0.92 & 4.67 & 0.89 & 0.085 \\
\hline Performing a pelvic exam without consent & 4.78 & 0.73 & 4.93 & 0.26 & 4.83 & 0.82 & 0.462 \\
\hline Not offering measures for pain & 4.43 & 0.85 & 4.86 & 0.36 & 4.74 & 0.88 & 0.001 \\
\hline Encouraging the use of an epidural & 3.93 & 0.99 & 4.00 & 1.03 & 4.41 & 0.88 & 0.009 \\
\hline Not preserving privacy & 4.76 & 0.73 & 5.00 & 0.00 & 4.76 & 0.84 & 0.313 \\
\hline $\begin{array}{l}\text { Convincing the woman to undergo a caesarean } \\
\text { section to end labour quickly and without pain }\end{array}$ & 4.45 & 0.95 & 4.64 & 0.49 & 4.74 & 0.85 & 0.031 \\
\hline Not considering the woman's decision & 4.75 & 0.65 & 4.93 & 0.26 & 4.78 & 0.84 & 0.310 \\
\hline Taking pictures without permission & 4.78 & 0.76 & 5.00 & 0.00 & 4.80 & 0.83 & 0.351 \\
\hline Enforcing the lithotomy position & 3.30 & 1.25 & 3.00 & 1.67 & 4.22 & 0.94 & $\leq 0.001$ \\
\hline Allowing accompaniment during the second stage & 2.99 & 1.55 & 2.71 & 1.63 & 2.76 & 1.66 & 0.691 \\
\hline Performing routine episiotomy & 4.39 & 0.98 & 4.40 & 1.07 & 4.24 & 1.03 & 0.448 \\
\hline Saying "You do not know how to push" & 4.72 & 0.80 & 5.00 & 0.00 & 4.76 & 0.84 & 0.238 \\
\hline Performing the Kristeller manoeuvre & 4.60 & 0.75 & 3.92 & 1.16 & 4.00 & 1.09 & $\leq 0.001$ \\
\hline Performing an episiotomy without anaesthesia & 4.46 & 1.01 & 3.89 & 1.05 & 4.17 & 1.61 & 0.046 \\
\hline
\end{tabular}


Table 4. Cont.

\begin{tabular}{|c|c|c|c|c|c|c|c|}
\hline & \multicolumn{7}{|c|}{ Area of Study } \\
\hline & \multicolumn{2}{|c|}{ Nursing } & \multicolumn{2}{|c|}{ Medicine } & \multicolumn{2}{|c|}{ Midwifery } & \multirow{2}{*}{$p^{1}$} \\
\hline & $M$ & $S D$ & $M$ & $S D$ & $M$ & $S D$ & \\
\hline Prohibiting eating and drinking & 3.54 & 1.12 & 3.31 & 1.54 & 3.93 & 1.02 & 0.108 \\
\hline Not providing covering/heating during delivery & 4.40 & 0.87 & 4.62 & 0.65 & 4.59 & 0.88 & 0.252 \\
\hline Saying "Stop complaining; it is not that bad" & 4.75 & 0.77 & 5.00 & 0.00 & 4.78 & 0.84 & 0.272 \\
\hline Not letting the woman shout & 4.48 & 0.93 & 4.98 & 0.28 & 4.50 & 1.04 & 0.193 \\
\hline Performing a caesarean section due to slow dilation & 4.00 & 1.14 & 4.23 & 0.92 & 4.33 & 0.96 & 0.249 \\
\hline $\begin{array}{l}\text { Performing an emergency caesarean section } \\
\text { without consent }\end{array}$ & 4.33 & 1.11 & 4.69 & 0.63 & 4.54 & 0.95 & 0.376 \\
\hline $\begin{array}{l}\text { Not allowing accompaniment in cases of } \\
\text { instrumentation or caesarean section }\end{array}$ & 4.54 & 0.79 & 4.08 & 1.11 & 4.17 & 0.90 & 0.012 \\
\hline Immediately cutting the cord & 3.60 & 1.26 & 2.82 & 1.40 & 4.15 & 1.03 & 0.003 \\
\hline Suturing a tear without anaesthesia & 4.37 & 0.94 & 4.58 & 0.66 & 4.48 & 0.96 & 0.588 \\
\hline Separating the mother and newborn & 4.88 & 0.60 & 5.00 & 0.00 & 4.80 & 0.83 & 0.646 \\
\hline $\begin{array}{l}\text { Allowing skin-to-skin contact after the paediatric } \\
\text { examination }\end{array}$ & 3.93 & 1.34 & 3.15 & 1.51 & 4.00 & 1.26 & 0.119 \\
\hline Taking the baby to the nursery & 3.85 & 1.12 & 3.15 & 1.14 & 4.11 & 1.05 & 0.015 \\
\hline Giving formula without the mother's consent & 4.72 & 0.81 & 4.92 & 0.27 & 4.78 & 0.84 & 0.482 \\
\hline
\end{tabular}

${ }^{1}$ Kruskal-Wallis test.

\section{Discussion}

In the present study, the psychometric properties of the PercOV-S instrument, which assesses health sciences students' perceptions in relation to OV, were explored. The internal reliability of the instrument was excellent, and the factor analysis explained $54.47 \%$ of the variance in 2 domains that could be defined as (domain 1) non-protocolized-invisible OV and (domain 2) protocolized-visible OV. Observing the factorial load of each of the items, its distribution in each of the domains and the number of items associated with each of the domains, it is easy to see that this type of violence against women may represent the tip of an iceberg model. As other reports of violence against women have shown, a very substantial part of this type of violence remains hidden [30] and it is difficult to identify for various reasons. OV, therefore, as a type of violence against women, cannot be represented in any other way.

Regarding the protocolized-visible OV (domain 2), it can be observed that all items associated with this domain are interventions that are usually protocolized in health centres. This domain has been called visible given that these practices have been the norm for a long time, and even today, they remain in force in many health centres despite not being recommended by scientific evidence and woman-focused care [29]. The WHO already recognized that "Studies have shown that a substantial proportion of healthy pregnant women undergo at least one clinical intervention during labour and birth, such as labour induction, oxytocin augmentation, caesarean section, operative vaginal birth or episiotomy. In addition, women in labour continue to be subjected to ineffective and potentially harmful routine interventions, such as perineal shaving, enemas, amniotomy, intravenous fluids, antispasmodics and antibiotics for uncomplicated vaginal births. This interventionist approach is not adequately sensitive to the woman's (and her family's) personal needs, values and preferences and can weaken her own capability during childbirth and negatively impact her childbirth experience" [31]. Regarding certain practices as a standard or protocol contributes to their normalization without taking into account aspects as basic as the woman's own opinion or decisions [22,32]. In addition, this normalization can be seen when comparing the results obtained in this study for domain 1 and domain 2 of the instrument; this comparison showed a notably lower mean for domain 2 (visible) and notably lower scores for the items related to this domain. Consequently, it is not surprising that these interventions are performed on women who come to a health centre to give birth. In other words, normalization of these interventions seems to be present. 
On the other hand, according to some authors, the lack of respect for women in delivery rooms has become a dynamic reflecting a lack of ethics and professionalism, which has led to ever-increasing investigations into the status of certain obstetric practices $[33,34]$. Regarding this point, a large proportion of non-protocolized or invisible OV was identified in this study. This broad factor encompasses practices such as lack of respect, violent language or the use of prohibited practices, such as the performance of the Kristeller manoeuvre; however, although it is known that such practices occur in delivery rooms, they are difficult to identify due to factors such as the lack of recording of the clinical histories of births [35]. Regarding this factor, it is worth noting the low factorial load of the item related to allowing "skin-on-skin contact after the paediatric examination", which the authors decided to maintain nonetheless since it is the only item that refers to this practice. After long reflection, the authors consider that this item may need a separate domain due to the importance and consequences of this practice on the physical and psychological health of both the mother and the baby and on the link between the two [36].

Regarding the sample, the high percentage of female participants $(89.5 \%)$ is notable; it may have been motivated by the topic being addressed or due to the fact that female representation in the health sciences is increasing $[37,38]$. The obtained results show that women perceive OV more than men in a wide range of interventions, possibly because they already have identified some gynaecological or obstetric practices as unpleasant due to their own experience in this area. Therefore, they may be more sensitized [12].

When the results were compared in terms of the participants' area of study, it was observed that the midwifery students perceived more OV in many of the items of the instrument; the same observation was true for the total score and the non-protocolized-invisible. It is noteworthy that midwifery students scored highest on items such as "not offering measures to treat pain", but it can be understood that, from a salutogenesis approach, the process of pregnancy and childbirth is studied as a physiological process and health process in women's sexual and reproductive life [39]; therefore, it may be that offering some measures to treat pain disrupts the physiology of these processes [40]. Other items that were statistically significantly higher among the midwifery students and where midwives perceived more OV were related to performing the Kristeller manoeuvre, performing an episiotomy without anaesthesia, and not allowing the woman to be accompanied if the delivery is instrumented and if a caesarean section will be performed. It is known that, in Spain, the Kristeller manoeuvre is performed in $25 \%$ of vaginal births and that, despite being recognized by professionals as a practice that is not free of risks (which are unilaterally assumed), it is practised in secret and health care providers describe how they learn and practice this manoeuvre [35]; therefore, it is evident that it is still being learned and put into practice in Spanish delivery rooms. For episiotomy without anaesthesia, midwives may feel that an episiotomy should only be performed if there is clinical need and that anaesthesia should only be administered in cases of emergency due to acute foetal compromise [29] based on the salutogenesis approach highlighted above. Finally, with regard to accompaniment in cases of instrumentation or caesarean section, it is known that nurses and midwives should be the guardians and guarantors of women's rights [12], but when these interventions are carried out, gynaecology and anaesthesia professionals become involved, shifting the role of the midwife and nurse to the background [24] and perhaps impacting the continuity of care and the woman's satisfaction with that care [41].

With all these findings, it seems that health science students have a role that may be important in the detection and prevention of obstetric violence. Being able to detect this type of violence, learning how to treat women from a comprehensive perspective and integrating this knowledge from the beginning of their learning can be essential parts of preventing obstetric violence.

Regarding PercOV-S results according to whether the participant had undergone internships in obstetrics-gynaecology departments and had attended a birth, it was striking that, for the overall score and the non-protocol-invisible domain, students who had participated in internships and/or who had witnessed a birth were better able to perceive OV than students who had not been on rotation for these services. The fact that students are able to identify certain practices as OV does not mean that they 
are on track to addressing this type of violence. Although identification is a beginning, one must also be aware that students also learn how to justify this learned violence, lack of respect, and abuse in delivery and maternity wards [24]. This presents a broad field for future lines of research in this area, with a fundamental role being played by the development of strategies and learning plans related to any violence against women, for example, domestic violence during pregnancy [42].

Finally, it should be noted that, although there were statistically significant differences according to the participants' personal experience with pregnancies and births for a considerable number of items on the PercOV-S scale, it was the portion of the sample that had no experience that scored highest in the global score, the visible domain, the invisible domain and some specific items. This result is very striking since it can be associated with the normalization of OV during the sexual and reproductive life of women, which leads to certain practices not being perceived as violent or abusive [43]. However, it is also true that these results should be interpreted with caution since they may be due to the limited representativeness of the sample in terms of the evaluated sociodemographic aspects. Other limitations of the study may be associated with not having conducted a panel of experts with a robust methodology such as that proposed by Polit et al. [44] for content validity of the PercOV-S instrument, even so the results seem consistent. Although registering 5 subjects per item is appropriate, the final sample of the study was too adjusted; this sample should be larger in future studies. Finally, another limitation of the study may be related to the impossibility of performing a temporal stability test, although this test is expected to be carried out in future studies as well as a confirmatory study of the factorial analysis; therefore, the results of this study should be taken with caution.

\section{Conclusions}

The psychometric properties of the PercOV-S instrument, which assesses health sciences students' perceptions in relation to OV, were explored. According to the results of this study, the instrument comprised 33 items rated on a Likert scale. The constructed instrument has a high degree of reliability and internal validity. Construct analysis yielded adequate results, and factor analysis indicated that $54.47 \%$ of the variance of the instrument was explained through 2 domains: (1) protocolized-visible OV and (2) non-protocolized-invisible OV. The distribution and content of these two factors are considered closely related to this type of violence against women, which can be compared to an iceberg in which only a small proportion is visible and a large mass is hidden. Specific training for health professionals in relation to obstetric violence is necessary, as it can be a key element in the prevention of this type of violence. On the other hand, the existence of statistically significant relationships between the sociodemographic variables collected and the global measurements according to the domains of the PercOV-S scale, was observed, highlighting the need to focus on normalization of OV as a central factor in future studies.

Author Contributions: D.M.-T. conceived and designed the study. D.M.-T. and M.J.A.-A. collected the data and worked on the database. D.M.-T. analysed and interpreted the data and wrote the article. V.M.G.-C.; L.A.-P. and A.C.-G. supervised the entire process, reviewed the article and made important intellectual contributions. All authors have read and agreed to the published version of the manuscript.

Funding: This research received no external funding.

Conflicts of Interest: The authors declare no conflict of interest.

\section{References}

1. Šimonović, D. A Human Rights-Based Approach to Mistreatment and Violence against Women in Reproductive Health Services with a Focus on Childbirth and Obstetric Violence; UN: New York, NY, USA, 2019.

2. D'Gregorio, R.P. Obstetric violence: A new legal term introduced in Venezuela. Int. J. Gynecol. Obstet. 2010, 111, 201-202. [CrossRef]

3. World Health Organization. The Prevention and Elimination of Disrespect and Abuse during Facility-Based Childbirth; WHO/RHR/14.23; World Health Organization: Geneva, Switzerland, 2014. 
4. Miller, S.; LaLonde, A. The global epidemic of abuse and disrespect during childbirth: History, evidence, interventions, and FIGO's mother-baby friendly birthing facilities initiative. Int. J. Gynecol. Obstet. 2015, 131, S49-S52. [CrossRef] [PubMed]

5. Taghizadeh, Z.; Irajpour, A.; Arbabi, M. Mothers' Response to Psychological Birth Trauma: A Qualitative Study. Iran. Red Crescent Med. J. 2013, 15, e10572. [CrossRef] [PubMed]

6. Iglesias, S.; Conde, M.; González, S.; Parada, M.E. ¿Violencia obstétrica en España, realidad o mito? 17.000 mujeres opinan. MUSAS 2019, 4, 77-97. [CrossRef]

7. Castro, R.; Frías, S.M. Obstetric Violence in Mexico: Results From a 2016 National Household Survey. Violence Against Women 2019, 26, 555-572. [CrossRef]

8. Vedam, S.; Stoll, K.; Taiwo, T.K.; Rubashkin, N.; Cheyney, M.; Strauss, N.; McLemore, M.; Cadena, M.; Nethery, E.; Rushton, E.; et al. The Giving Voice to Mothers study: Inequity and mistreatment during pregnancy and childbirth in the United States. Reprod. Health 2019, 16, 1-18. [CrossRef]

9. Meijer, M.; Brandão, T.; Cañadas, S.; Falcon, K. Components of obstetric violence in health facilities in Quito, Ecuador: A descriptive study on information, accompaniment, and position during childbirth. Int. J. Gynecol. Obstet. 2019, 148, 355-360. [CrossRef]

10. Ishola, F.; Owolabi, O.; Filippi, V. Disrespect and abuse of women during childbirth in Nigeria: A systematic review. PLoS ONE 2017, 12, e0174084. [CrossRef]

11. Mselle, L.T.; Kohi, T.W.; Dol, J. Barriers and facilitators to humanizing birth care in Tanzania: Findings from semi-structured interviews with midwives and obstetricians. Reprod. Health 2018, 15, 137. [CrossRef]

12. Siraj, A.; Teka, W.; Hebo, H. Prevalence of disrespect and abuse during facility based child birth and associated factors, Jimma University Medical Center, Southwest Ethiopia. BMC Pregnancy Childbirth 2019, 19, 185. [CrossRef]

13. Bhattacharya, S.; Ravindran, T.K.S. Silent voices: Institutional disrespect and abuse during delivery among women of Varanasi district, northern India. BMC Pregnancy Childbirth 2018, 18, 1-8. [CrossRef] [PubMed]

14. Begley, C.; Sedlicka, N.; Daly, D. Respectful and disrespectful care in the Czech Republic: An online survey. Reprod. Health 2018, 15, 198. [CrossRef] [PubMed]

15. Ravaldi, C.; Skoko, E.; Battisti, A.; Cericco, M.; Vannacci, A. Sociodemographic characteristics of women participating to the LOVE-THEM (Listening to Obstetric Violence Experiences THrough Enunciations and Measurement) investigation in Italy. Data Brief 2018, 19, 226-229. [CrossRef] [PubMed]

16. Priddis, H.S.; Keedle, H.; Dahlen, H. The Perfect Storm of Trauma: The experiences of women who have experienced birth trauma and subsequently accessed residential parenting services in Australia. Women Birth 2018, 31, 17-24. [CrossRef]

17. Coates, D.; Donnolley, N.; Foureur, M.; Henry, A. Women's experiences of decision-making and attitudes in relation to induction of labour: A survey study. Women Birth 2020, 19, 1871-5192. [CrossRef]

18. Chattopadhyay, S.; Mishra, A.; Jacob, S. 'Safe', yet violent? Women's experiences with obstetric violence during hospital births in rural Northeast India. Cult. Health Sex. 2018, 20, 815-829. [CrossRef]

19. Guillén, F.F. What Is Obstetric Violence? Some Social, Ethical and Legal Aspects. Dilemata Int. J. Appl. Ethics. 2015, 7, 113-128.

20. Sadler, M.; Santos, M.J.; Ruiz-Berdún, D.; Rojas, G.L.; Skoko, E.; Gillen, P.; Clausen, J.A. Moving beyond disrespect and abuse: Addressing the structural dimensions of obstetric violence. Reprod. Health Matters 2016, 24, 47-55. [CrossRef]

21. Olza-Fernández, I.; Ruiz-Berdún, D. Midwifes Experiences Regarding Obstetric Violence. In Archives of Women's Mental Health; Springer: Berlin/Heidelberg, Germany, 2015. [CrossRef]

22. Borges, M.T. A Violent Birth: Reframing Coerced Procedures During Childbirth as Obstetric Violence. Duke Law J. 2018, 67, 827-862.

23. Diniz, C.S.G.; Rattner, D.; D'Oliveira, A.F.P.L.; De Aguiar, J.M.; Niy, D.Y. Disrespect and abuse in childbirth in Brazil: Social activism, public policies and providers' training. Reprod. Health Matters 2018, 26, 19-35. [CrossRef]

24. Rominski, S.D.; Lori, J.; Nakua, E.; Dzomeku, V.; Moyer, C.A. When the baby remains there for a long time, it is going to die so you have to hit her small for the baby to come out: Justification of disrespectful and abusive care during childbirth among midwifery students in Ghana. Health Policy Plan. 2016, 32. [CrossRef] [PubMed]

25. Carretero-Dios, H.; Pérez, C. Normas Para El Desarrollo y Revisión de Estudios Instrumentales. Int. J. Clin. Health Psychol. 2005, 5, 521-551. 
26. Anthoine, E.; Moret, L.; Regnault, A.; Sébille, V.; Hardouin, J.B. Sample size used to validate a scale: A review of publications on newly-developed patient reported outcomes measures. Health Qual. Life Outcomes 2014, 12,1-10. [CrossRef]

27. Chadha, N.K. Applied Psychometry, 1st ed.; Routledge: London, UK, 2009.

28. Brandão, T.; Cañadas, S.; Galvis, A.; de los Ríos, M.M.; Meijer, M.; Falcon, K. Childbirth experiences related to obstetric violence in public health units in Quito, Ecuador. Int. J. Gynecol. Obstet. 2018, 143, 84-88. [CrossRef]

29. Ministerio de Sanidad. Guía de Práctica Clínica Sobre La Atención Al Parto Normal; Ministerio de Sanidad: Vitoria-Gasteiz, Spain, 2010.

30. Ministerio de la Presidencia, Relacones con las Cortes e Igualdad. Estudio Sobre El Tiempo Que Tardan Las Mujeres Víctimas de Violencia de Género En Verbalizar Su Situación; Centro de Publicaciones Complejo Moncloa: Madrid, Spain, 2019.

31. World Health Organization. WHO Recommendations: Intrapartum Care for a Positive Childbirth Experience; World Health Organization: Geneva, Switzerland, 2018.

32. Freedman, L.P.; Schaaf, M. Act global, but think local: Accountability at the frontlines. Reprod. Health Matters 2013, 21, 103-112. [CrossRef]

33. Bradley, S.; McCourt, C.; Rayment, J.; Parmar, D. Midwives' perspectives on (dis)respectful intrapartum care during facility-based delivery in sub-Saharan Africa: A qualitative systematic review and meta-synthesis. Reprod. Health 2019, 16, 1-16. [CrossRef] [PubMed]

34. Bradley, S.; McCourt, C.; Rayment, J.; Parmar, D. Disrespectful intrapartum care during facility-based delivery in sub-Saharan Africa: A qualitative systematic review and thematic synthesis of women's perceptions and experiences. Soc. Sci. Med. 2016, 169, 157-170. [CrossRef] [PubMed]

35. Rubashkin, N.; Torres, C.; Escuriet, R.; Ruiz-Berdún, D. "Just a little help": A qualitative inquiry into the persistent use of uterine fundal pressure in the second stage of labor in Spain. Birth 2019, 46, 517-522. [CrossRef]

36. Widström, A.M.; Brimdyr, K.; Svensson, K.; Cadwell, K.; Nissen, E. Skin-to-skin contact the first hour after birth, underlying implications and clinical practice. Acta Paediatr. 2019, 108, 1192-1204. [CrossRef]

37. Bernalte-Martí, V. The Minority of Male in the Nursing Profession. Reflexions of Their History, Image and Their Evolution in Spain. Enermería Glob. 2015, 14, 328-334.

38. Instituto Nacional de Estadística. Número de Enfermeros por Comunidades, Ciudades Autónomas y Provincias de Colegiación, Edad y Sexo. Available online: https://www.ine.es/jaxi/Tabla.htm?path=/t15/p416/ a2016/10/\&file=s08002.px\&L=0 (accessed on 31 July 2020).

39. Ali, S.A.-S.K.; Ahmed, H.M. Effect of Change in Position and Back Massage on Pain Perception during First Stage of Labor. Pain Manag. Nurs. 2018, 19, 288-294. [CrossRef]

40. Anim-Somuah, M.; Smyth, R.M.D.; Cyna, A.M.; Cuthbert, A. Epidural versus non-epidural or no analgesia for pain management in labour. Cochrane Database Syst. Rev. 2018, 5, CD000331. [CrossRef] [PubMed]

41. Sandall, J.; Soltani, H.; Gates, S.; Shennan, A.; Devane, D. Midwife-Led Continuity Models versus Other Models of Care for Childbearing Women (Review) Summary Findings for the Main Comparison. Cochrane Database Syst. Rev. 2016, 4. [CrossRef]

42. Procentese, F.; Arcidiacono, C.; Di Napoli, I.; Tuccillo, F.; Chiurazzi, A. Healthcare Professionals' Perceptions and Concerns towards Domestic Violence during Pregnancy in Southern Italy. Int. J. Environ. Res. Public Health 2019, 16, 3087. [CrossRef] [PubMed]

43. Mena-Tudela, D.; González-Chordá, V.M.; Soriano-Vidal, F.J.; Bonanad-Carrasco, T.; Centeno-Rico, L.; Vila-Candel, R.; Castro-Sánchez, E.; Gasch, Á.C. Changes in health sciences students' perception of obstetric violence after an educational intervention. Nurse Educ. Today 2020, 88, 104364. [CrossRef]

44. Polit, D.F.; Beck, C.T.; Owen, S.V. Is the CVI an acceptable indicator of content validity? Appraisal and recommendations. Res. Nurs. Health 2007, 30, 459-467. [CrossRef]

Publisher's Note: MDPI stays neutral with regard to jurisdictional claims in published maps and institutional affiliations. 